\title{
A comparative human rights analysis of laws and policies for adolescent contraception in Uganda and Kenya
}

Katrina Perehudoff ${ }^{1,2,3^{*}+}$ (D) Denis Kibira ${ }^{4,6+}$, Elke Wuyts ${ }^{1}$, Carles Pericas ${ }^{1}$, Joyce Omwoha ${ }^{3,5}$, Hendrika A. van den Ham ${ }^{6}$, Aukje K. Mantel-Teeuwisse ${ }^{6}$ and Kristien Michielsen 1,3

\begin{abstract}
Background: Improving access to adolescent contraception information and services is essential to reduce unplanned adolescent pregnancies and maternal mortality in Uganda and Kenya, and attain the SDGs on health and gender equality. This research studies to what degree national laws and policies for adolescent contraception in Uganda and Kenya are consistent with WHO standards and human rights law.

Methods: This is a comparative content analysis of law and policy documents in force between 2010 and 2018 governing adolescent (age 10-19 years) contraception. Between and within country differences were analysed using WHO's guidelines "Ensuring human rights in the provision of contraceptive information and services".

Results: Of the 93 laws and policies screened, 26 documents were included (13 policies in Uganda, 13 policies in Kenya). Ugandan policies include a median of $1 \mathrm{WHO}$ recommendation for adolescent contraception per policy (range $0-4$ ) that most frequently concerns contraception accessibility. Ugandan policies have $6 / 9 \mathrm{WHO}$ recommendations (14/24 sub-recommendations) and miss entirely WHO's recommendations for adolescent contraception availability, quality, and accountability. On the other hand, most Kenyan policies consistently address multiple WHO recommendations (median 2 recommendations/policy, range $0-6$ ), most frequently for contraception availability and accessibility for adolescents. Kenyan policies cover 8/9 WHO recommendations (16/24 sub-recommendations) except for accountability.

Conclusions: The current policy landscapes for adolescent contraception in Uganda and Kenya include important references to human rights and evidence-based practice (in WHO's recommendations); however, there is still room for improvement. Aligning national laws and policies with WHO's recommendations on contraceptive information and services for adolescents may support interventions to improve health outcomes, provided these frameworks are effectively implemented.
\end{abstract}

Keywords: Adolescent pregnancy, Contraception, Human rights, Health policy, Uganda, Kenya

*Correspondence: katrina.perehudoff@gmail.com

†Katrina Perehudoff and Denis Kibira shared first authorship

1 International Centre for Reproductive Health, Department of Public

Health and Primary Care, Ghent University, C. Heymanslaan 10, 9000 Gent,

Belgium

Full list of author information is available at the end of the article

(c) The Author(s) 2022. Open Access This article is licensed under a Creative Commons Attribution 4.0 International License, which permits use, sharing, adaptation, distribution and reproduction in any medium or format, as long as you give appropriate credit to the original author(s) and the source, provide a link to the Creative Commons licence, and indicate if changes were made. The images or other third party material in this article are included in the article's Creative Commons licence, unless indicated otherwise in a credit line to the material. If material is not included in the article's Creative Commons licence and your intended use is not permitted by statutory regulation or exceeds the permitted use, you will need to obtain permission directly from the copyright holder. To view a copy of this licence, visit http://creativecommons.org/licenses/by/4.0/. The Creative Commons Public Domain Dedication waiver (http://creativeco mmons.org/publicdomain/zero/1.0/) applies to the data made available in this article, unless otherwise stated in a credit line to the data. 


\section{Plain language summary}

The unmet need for contraception among adolescents is high in Uganda and Kenya, and has many negative consequences, including unwanted pregnancy, exposure to unsafe abortion, and maternal morbidity and mortality. National laws and policies play an important role in determining adolescents'access to contraception. For example, national laws and policies can shape the government programs that provide (or withhold) contraception, and the social norms influencing adolescents' access to contraception. Therefore, this research compares national laws and policies that determine access to contraception services and information for adolescents in Uganda and Kenya with WHO's recommendations for access to contraception.

This is an analysis of the content of Ugandan and Kenyan laws and policies in force between 2010 and 2018. The content of these documents was analyzed using WHO's nine recommendations for how contraception information and services should be provided: non-discrimination, availability, accessibility, acceptability, quality, informed decisionmaking, confidentiality, participation, accountability.

Ninety-three documents were screened and 26 documents were included in the analysis: 13 policies from Uganda and 13 policies from Kenya. On average, Ugandan policies include one WHO recommendation for adolescent contraception per policy and Kenyan policies include two WHO recommendations. This recommendation most frequently mentioned in all policies is the accessibility of contraception (for example, for adolescents living remotely, integrated in adolescent HIV or pre-/post-natal care, etc.). Together, all Ugandan policies mentioned 6/9 WHO recommendations whereas all Kenyan policies cover $8 / 9$ WHO recommendations.

In conclusion, Ugandan and Kenyan policies are consistent with many of WHO's recommendations for access to contraception, however, there is still room for improvement.

\section{Background}

The 2030 Agenda for Sustainable Development seeks to improve gender equality (Sustainable Development Goal (SDG) 5) and reduce maternal mortality (SDG 3), which claims the lives of 289,000 women annually [1]. Worldwide, pregnancy-related causes are the leading cause of death among women aged 15-24 and this is mostly in low- and middle-income countries [2]. Improving access to contraceptive information and services is essential to reduce maternal mortality $[3,4]$.

Achieving the SDG goals requires adopting supportive national sexual and reproductive health (SRH) laws and policies and repealing regressive legal rules, for example restrictions on contraception and abortion services. Recent changes in global and national SRH policies illustrate that the policy making process is dynamic and complex, sometimes leading to public health decisions unsupported by evidence and/or human rights by governments, public health officials, health providers, and/ or other SRH actors [5]. In the case of access to contraception for adolescents, one school of thought favours restricting access based on the notion of traditional morals, values, and culture; while another school of thought promotes contraceptive access based on the best medical evidence and human rights law [6]. In this paper we refer to adolescents as people aged $10-19$ years as defined by the World Health Organisation (WHO).

Both Uganda and Kenya have a high maternal mortality rate (336 and 362 per 100,000 live births, respectively), a low prevalence of modern contraceptive use among adolescents aged 15-19 years in union ( $7 \%$ and $20 \%$ respectively,) and high fertility rates among adolescents aged $15-19$ years $((132 / 1000$ and $96 / 1000$ women, respectively), respectively) $[7,8]$. During the tenure of the Millennium Development Goals (MDGs), both governments modestly improved contraceptive uptake with the use of modern contraceptives among married women increasing in Uganda from 18 (2001) to 35\% (2016) and in Kenya from 31.5 (2003) to $53 \%$ (2014) and adopted laws and policies promoting adolescent contraception $[9,10]$. These achievements were realised against the backdrop of restrictive gender norms, some political opposition often from religious communities, and negative media messages about contraception [11]. The Ugandan government's decision to endorse the 2018 National Sexuality Education Framework made significant headlines by effectively abolishing comprehensive sexuality education for adolescents including contraception in favour of a values-based approach that favours abstinence promotion $[12,13]$.

National law and policy are important tools that shape legal obligations, government programmes, social norms, and the potential to hold governments accountable for fulfilling girls' and women's health rights [1]. The East African Community (EAC), a regional intergovernmental organisation including Kenya and Uganda, adopted the HIV \& AIDS Prevention and Management Act in 2012 that requires EAC 
States to take a rights-based approach to ensuring adolescents have access to SRH information and education, including about contraception [14].

It is unclear to what extent the national laws and policies in Kenya and Uganda uphold contraceptive availability, accessibility, acceptability, quality, freedom from discrimination, and other standards in the WHO's guidance document called "Ensuring human rights in the provision of contraceptive information and services" [15]. WHO's guidelines offer a global standard of evidenceinformed and human rights-based recommendations for adolescent contraception; they have been used to analyse domestic law and policy in South Africa, the Philippines, and Paraguay, as well as to guide country-level action [16-20]. Failing to address the norms underlying law, policy, and public health practice may be why some micro-level interventions and programmes are unable to deliver improved adolescent SRH outcomes [21]. Laws and policies that protect and promote adolescents' access to safe and affordable contraception of assured quality in a non-discriminatory manner can create a supportive environment for the enjoyment of their rights, poverty reduction, and sustainable development.

\section{Methods}

This article aims to assess to what degree national laws and policies for adolescent contraception (2010-2018) in Uganda and Kenya are consistent with the global standards in the WHO's guidance. This study is a comparative content analysis of legislation and policy documents governing any aspect of adolescent contraception at the national level in Uganda and Kenya. As has been described in previous studies, we defined policy as principles or strategies for a plan of action designed to achieve a particular set of goals, including through guidelines, plans, and standards [22]. During the period 2010-2018 accelerated global efforts were undertaken to improve girls' and women's health, starting with the United Nations (UN) Secretary-General's Commission on LifeSaving Commodities (UNCOLSC, 2010) for Women and Children was set up [23] and in 2015, the UN Global Strategy for Women's and Children's and Adolescents' Health (UNGS WCAH, 2016-2030) was published [24]. A cut-off of 2018 was selected in order to catch the initial implementation of the UNGS WCAH.

\section{Data collection}

An online search (conducted in May 2019 and repeated in March 2021) identified relevant laws and policies that were in force between 2010 to 2018 through national government websites and legal databases (i.e. Uganda Legal Information Institute https://ulii.org/consol_legli st/consolidated_legislation, Kenya Law http://kenyalaw. org/kl/index.php?id=400, Kenyan Health Guidelines, Standards \& Policies Portal http://guidelines.health.go. ke, Ugandan Ministry of Health Knowledge Management Portal http://library.health.go.ug, International Labour Organisation NATLEX), reference lists in relevant academic commentary and publications, a Google search using the search syntax "((adolescent OR sexual OR Reproductive) health) AND (law or policy OR policies) AND Uganda/Kenya", and through crowdsourcing documents from our network.

Documents were selected for inclusion in three stages (See flow diagram in Fig. 1). First, legal, strategic, and policy documents addressing subjects related to adolescent health, SRH, and/or contraception were collected for further screening (See Additional file 1 for a complete list of these documents). Second, we applied the following two inclusion criteria: (1) document is legal, strategic, or policy-related; and (2) the document was in force between 2010 and 2018. We determined whether the document was in force by the term stated explicitly in the document or in a superseding document, the status of the document on a government website, or, in the absence of other available information, by assuming that policy documents have a lifespan of 10 years. Documents were excluded if they did not meet the inclusion criteria or if no full text was available. Third,

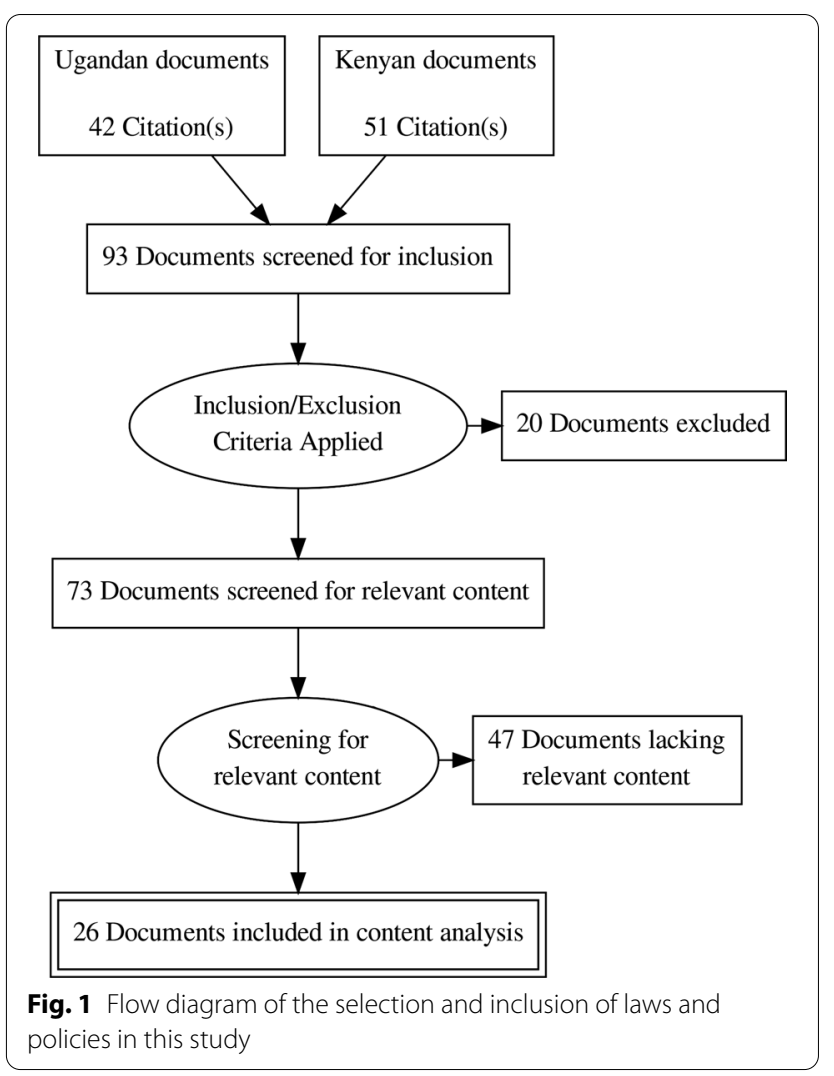


we scanned the full text to identify any explicit content related to the recommendations in WHO's guidance document called "Ensuring human rights in the provision of contraceptive information and services" ("WHO recommendations'). This resulted in a short list of documents that underwent content analysis (see Table 1) [15]. Finally, local policy experts (DK, DKA, JO, TSG) verified whether the shortlist of documents was accurate, complete, and up-to-date, and suggested other documents for consideration. Experts were co-authors (DK, Executive Director of a Ugandan health policy NGO; JO, Kenyan academic expert in gender policy) and project advisors (DKA, TSG-both are health lawyers with track records representing Ugandan and

Table 1 Ugandan and Kenyan laws and policies (in force between 2010 and 2018) included in content analysis

\begin{tabular}{|c|c|c|c|}
\hline Document title & Date of publication & Status* & Acronym in Fig. 1 \\
\hline \multicolumn{4}{|l|}{ Legal and policy documents from Uganda } \\
\hline Uganda Family Planning Cost Implementation Plan 2015-2020 (Ministry of Health) & 2015 & Current & UFPCIP \\
\hline $\begin{array}{l}\text { National HIV/AIDS Strategic Plan 2015-2020 and Priority Action Plan (Uganda AIDS Commission/ } \\
\text { Republic of Uganda) }\end{array}$ & 2015 & Current & NASP \\
\hline $\begin{array}{l}\text { Reducing Morbidity and Mortality from Unsafe Abortions Standards and Guidelines (Ministry of } \\
\text { Health) }\end{array}$ & 2015 & & RMMUA \\
\hline National Condom Programming Strategy 2013-2015 (Ministry of Health) & 2013 & & NCPS \\
\hline Adolescent Health Policy Guidelines and Service Standards (Ministry of Health) & 2012 & Current & AHPGSS \\
\hline National Strategic Plan for HIV/AIDS 2011-2015 (Republic of Uganda) & 2011 & & NSPHA \\
\hline National HIV Prevention Strategy for Uganda 2011-2015 (Republic of Uganda) & 2011 & & NHPS \\
\hline National HIV Testing Services Policy and Implementation Guidelines Uganda (Ministry of Health) & 2010 & & NHTSPIG \\
\hline $\begin{array}{l}\text { Reproductive Health Commodity Security Strategic Plan, 2009/10- 2013/14 (Ministry of Public } \\
\text { Health and Sanitation, Ministry of Medical Services) }\end{array}$ & 2009 & & RHCSSP \\
\hline $\begin{array}{l}\text { Roadmap for Accelerating the Reduction of Maternal and Neonatal Mortality and Morbidity in } \\
\text { Uganda (Republic of Uganda) }\end{array}$ & 2007 & & RMNMM \\
\hline National HIV/AIDS Strategic Plan 2007-2012 (Republic of Uganda) & 2007 & & NHSP \\
\hline National Policy Guidelines and Service Standards for SRH and Rights (Ministry of Health) & 2006 & & NPGSS \\
\hline National Adolescent Health Policy (Ministry of Health) & 2004 & & NAHP \\
\hline \multicolumn{4}{|l|}{ Legal and policy documents from Kenya } \\
\hline National Family Planning Costed Implementation Plan 2017-2020 (Ministry of Health) & 2017 & Current & KFPCIP \\
\hline $\begin{array}{l}\text { National Guidelines for Provision of Adolescent and Youth Friendly (AYF) Services in Kenya } \\
\text { (Ministry of Health) }\end{array}$ & 2016 & Current^ & NGPAYS \\
\hline National Adolescent Sexual and Reproductive Health (SRH) Policy 2015 (Ministry of Health) & 2015 & Current^ & ASRHP \\
\hline $\begin{array}{l}\text { Population Policy for National Development 2012-2030 (Ministry of State Planning, National } \\
\text { Development, and Vision 2030) }\end{array}$ & $2012-2030$ & Current & PPND \\
\hline $\begin{array}{l}\text { National Communication Strategy for Community Health Services 2012-2017 (Ministry of Public } \\
\text { Health \& Sanitation) }\end{array}$ & 2012 & Current* & NCSCHS \\
\hline $\begin{array}{l}\text { Towards the Elimination of Mother to Child Transmission (eMTCT) of HIV and Keeping Mothers } \\
\text { Alive- Strategic Framework 2012-2015 (Ministry of Health) }\end{array}$ & 2012 & Current* & MTCTSF \\
\hline $\begin{array}{l}\text { Reproductive Health Communication Strategy 2010-2012 (Ministry of Public Health \& Sanitation, } \\
\text { and Ministry of Medical Services) }\end{array}$ & 2010 & & RHCS \\
\hline $\begin{array}{l}\text { National Road Map for Accelerating the Attainment of the MDGs Related to Maternal Health and } \\
\text { Newborn Health in Kenya (Ministry of Public Health \& Sanitation) }\end{array}$ & 2010 & Current* & NRMMNH \\
\hline National Family Planning Guidelines for Service Providers (Ministry of Public Health \& Sanitation) & 2010 & & NFPGSP \\
\hline $\begin{array}{l}\text { National Reproductive Health Strategy 2009-2015 (Ministry of Public Health \& Sanitation, and } \\
\text { Ministry of Medical Services) }\end{array}$ & 2009 & Current* & NRHS \\
\hline $\begin{array}{l}\text { Strategy for Improving the Uptake of Long-acting and Permanent Methods of Contraception in } \\
\text { the Family Planning Program 2008-2010 (Ministry of Public Health \& Sanitation) }\end{array}$ & 2008 & & SULAR \\
\hline National Reproductive Health Policy (Ministry of Health) & 2007 & & NRHP \\
\hline $\begin{array}{l}\text { Adolescent Reproductive Health and Development Policy 2005-2015 Plan of Action (Ministry of } \\
\text { Planning \& Ministry of Health) }\end{array}$ & 2005 & Current* & ARHDP \\
\hline
\end{tabular}

A list of all documents reviewed for this study can be found in Additional file 1

AIDS acquired immunodeficiency syndrome, AYF adolescent- and youth-friendly, HIV human immunodeficiency virus, SRH sexual and reproductive health *In these cases the policy's explicit timeframe had lapsed yet the Ministry of Health still listed the document as 'current' $\wedge$ When not explicitly stated in the policy, we assume policies have a 10-year lifespan 
Kenyan NGOs (respectively) with a strong focus on SRH and rights) who have extensively engaged with $\mathrm{SRH}$ policies in their respective countries.

\section{Data analysis}

Three researchers (EW, CP, KP) were responsible for coding the documents and the data extraction. A pre-defined coding strategy and data extraction sheet was used, which was pre-tested by these researchers on legal and policy documents from South Africa.

During analysis the included documents were screened for content relating to adolescents, and excerpts were classified by two independent researchers (a medical doctor (CP) and, a health scientist (EW) both trained in health policy, and a health scientist trained in law (KP)) using WHO's nine recommendations and 24 sub-recommendations, which served as a coding matrix. See Table 2 for an overview of these recommendations.

Researchers used the coding matrix that scored the content based on references to: (1) adolescent contraception, or (2) contraception in general (not specifically related to adolescents). Discrepancies were deliberated until consensus was reached. The coding results were reviewed by two experts (DK, JO) with first-hand knowledge of the local policy context.

Three researchers (KP, CP, EW) investigated between and within country trends. The between-country analysis examined the similarities and differences in the overall legal and policy frameworks that are currently in force. The within-country descriptive analysis examined the evolution in the adolescent-related content of relevant laws and policies in force in both countries between 2000 and 2018.

A stakeholder validation meeting was held at the Ugandan Ministry of Health (MoH) on December 6th, 2019 to discuss the preliminary findings. Due to the Coronavirus pandemic a comparable stakeholder validation meeting in Kenya was not possible.

\section{Results}

Ninety-three documents were screened for inclusion. Of those, sixty-seven documents were excluded from content analysis because they were never adopted $(n=4)$; retired or superseded before $2010(\mathrm{n}=8)$; clinical in nature $(n=3)$; no full text was available $(n=5)$; or did not include content related to WHO's recommendations for contraception information and services $(n=47)$. This resulted in twenty-six documents being included in content analysis (see flow diagram in Fig. 1).

Of the included documents, 13 were from Uganda and 13 were from Kenya (Table 1).

\section{Adolescent contraception policy landscape}

National laws and policies currently in force in Uganda include six of the nine WHO recommendations (and $14 / 24$ sub-recommendations) and in Kenya they include eight of the nine WHO recommendations (and $16 / 24$ sub-recommendations) for adolescent contraception (Table 2).

National laws and policies addressed a median of one recommendation for adolescent contraception (range 0-4 recommendations) in Uganda and two recommendations for adolescent contraception (range 0-6 recommendations) in Kenya. Recommendations were concentrated in relatively few policies: Documents with four or more WHO recommendations were found in one Ugandan policy and four Kenyan policies (see Fig. 2). Below we present evidence for each recommendation related to adolescent contraception from the legal and policy documents currently in force in Uganda and Kenya (see Tables 1 and 2, and Fig. 2).

\section{Non-discrimination}

Non-discrimination refers to equal access that is free from discrimination, coercion or violence (recommendation 1.1(R1.1)). Uganda's Family Planning Cost Implementation Plan (2015-2020) seeks to increase age-appropriate knowledge and access to family planning amongst adolescents (ages 10-24 years), including to disadvantaged or marginalised populations through AYF corners and extended service delivery hours outside school hours (R1.2).

Kenya's National Adolescent SRH Policy (2015) foresees the provision of accurate information and services to prevent the early/unintended pregnancy. The Family Planning Cost Implementation Plan (20172020) focuses on social behavioural change communication strategy/policy, addressing myths and misconceptions about modern contraceptives; and providing information and services to special needs groups (ex. adolescents), and age-appropriate family planning information (R1.1, R1.2).

\section{Availability}

Availability requires that contraceptive commodities, supplies and equipment are integrated in the national essential medicine supply chain (R2.1). This was not addressed in relation to adolescent contraception in Uganda's policies currently in force.

Recommendation 2.1 was the most well covered domain in Kenyan policies. Availability is a focal point in the National Guidelines for Provision of Adolescent and Youth Friendly (AYF) Services (2016) (ex. a continuous 


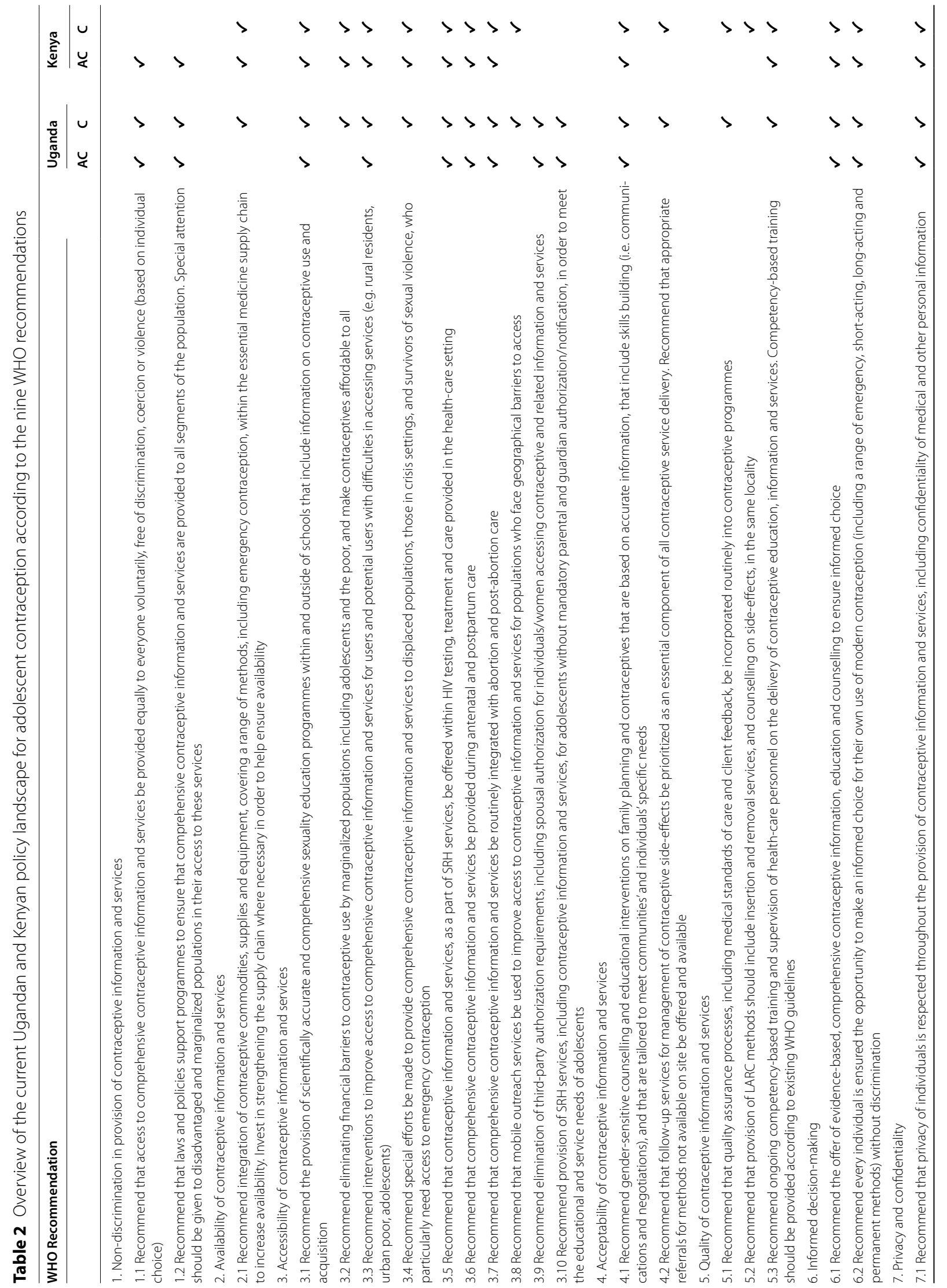




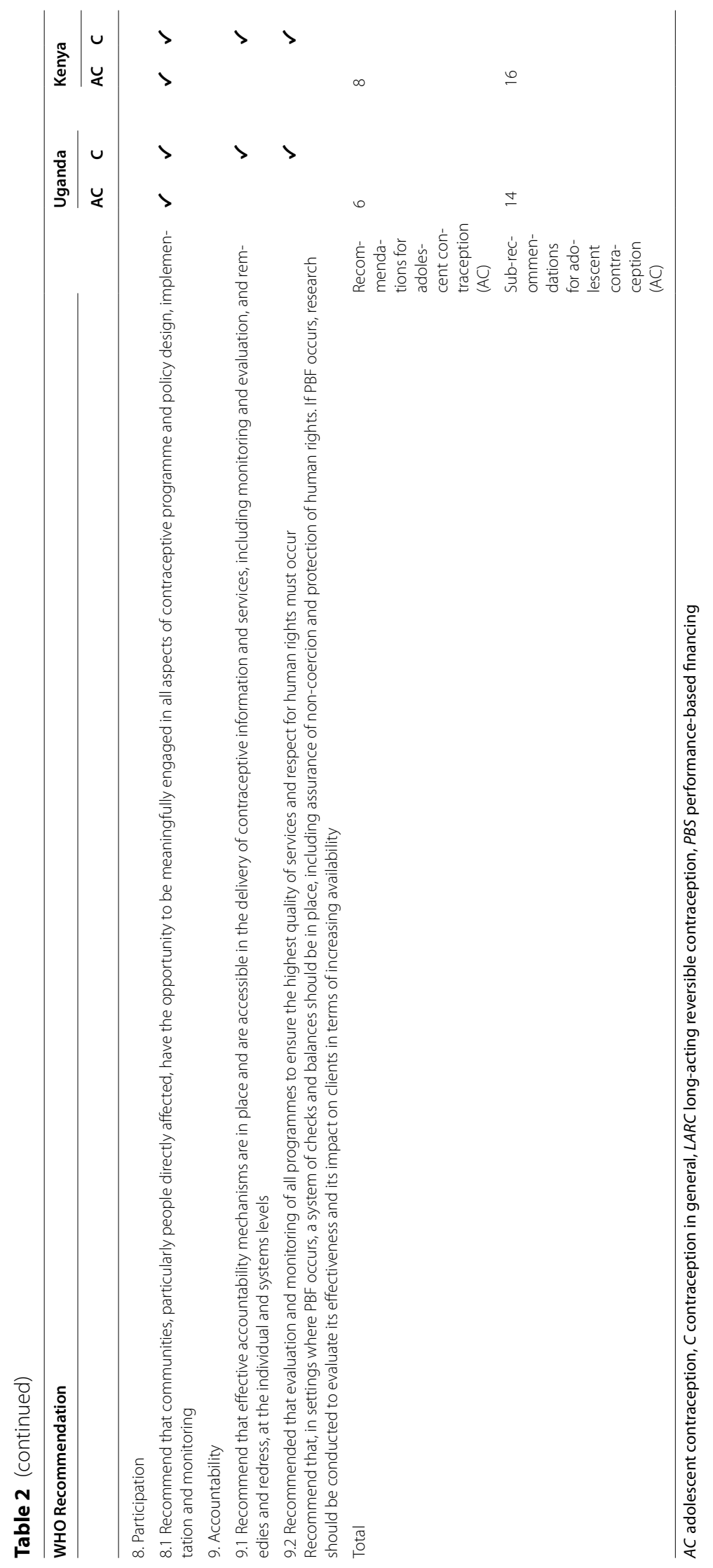




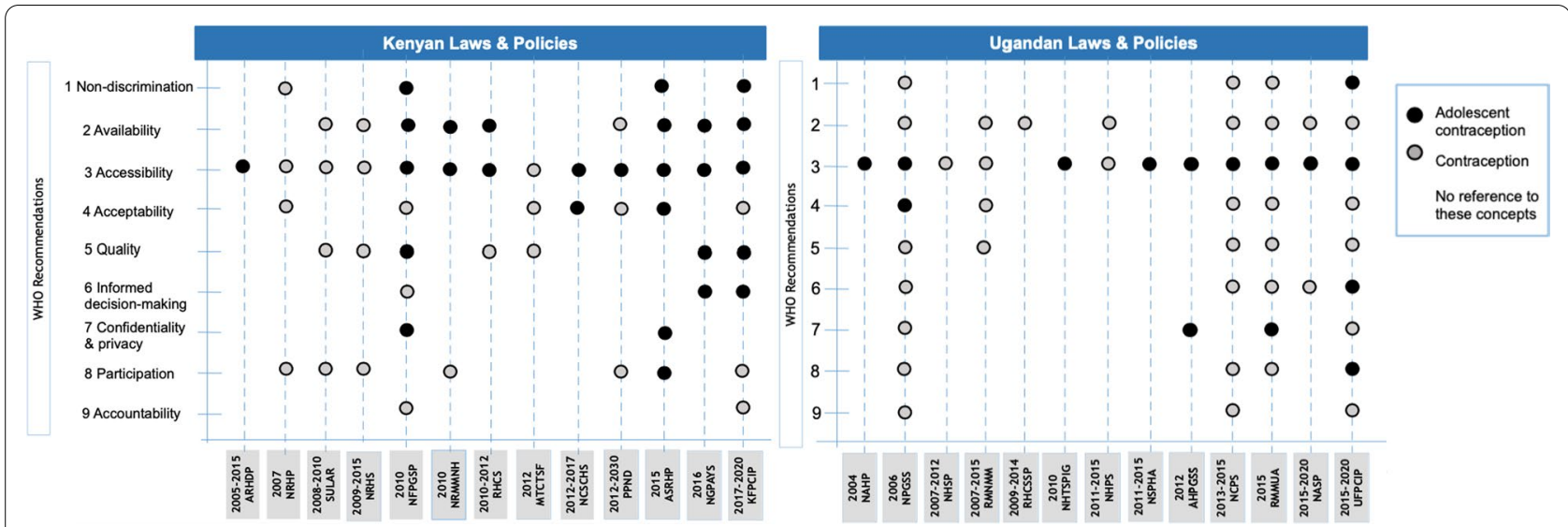

Fig. 2 Content of Ugandan and Kenyan policies in force between 2010 and 2018 addressing adolescent contraception

supply of essential medical commodities via AYF service delivery points).

\section{Accessibility}

Accessibility concerns barriers to access to contraceptive information and services including information and education, financing, geography, conflict and violence, integration in SRH, maternal, and/or abortion care, and third-party authorisation.

The Uganda Family Planning Cost Implementation Plan (2015-2020) seeks to increase adolescent's knowledge and empowerment to use family planning services and avoid teenage pregnancy through peer educators, print and online media targeting adolescents, and 'edutainment' community events. These measures neither mention the scientific basis nor comprehensiveness of information (required for R3.1). This policy also addresses the contraceptive needs of those with difficulty accessing services (R3.3) through AYF services, corners, and delivery hours (ex. outside school hours). Uganda's Adolescent Health Policy Guidelines and Service Standards (2012) require that adolescents have access to a range of SRH services, such as post abortion care and management (R3.7, R3.5 R3.6). Ugandan policies do not mention the elimination of financial barriers for adolescents (R3.2), provision to displaced adolescents, those in crisis settings, or survivors of violence (R3.4), nor the use of mobile outreach services to overcome geographic barriers to access (R3.8). The elimination of third party / parental authorisation in relation to adolescent contraception was not addressed in the policies currently in force (R3.9, R3.10).

Kenya's National Family Planning Cost Implementation Plan (2017-2020) addresses the contraceptive needs of those with difficulty accessing services (R3.3) through training and supporting peer educators, and through age-appropriate family planning information, and a provider-led approach to create demand for services among groups with special needs.

The National Guidelines for Provision of AYF Services (2016) define the essential package of services and information that must be available at AYF service points. The essential package integrates contraception counselling and provision of full range of contraceptive methods, including long-acting reversible contraceptive (LARC) methods, with other forms of SRH care (ex. HIV counselling, testing, and treatment) (R3.5), antenatal and postpartum care including pregnancy testing (R3.6), post abortion care (R3.7), and sexual and gender-based violence counselling, services and referrals (R3.4). The policy's four service delivery models aim to better reach adolescents through (1) community-based initiatives in non-medical settings to reach first time parents, fathers, and young mothers with limited mobility, (2) clinical settings, (3) school settings, and (4) virtually through digital platforms (R3.3). It also prescribes the Minimum Initial Service Package for Reproductive Health ('essential package'), which is a list of priority interventions designed to reduce mortality, morbidity, and disability among populations affected by crises. The Essential Package should ensure access to a broad mix of 'free' family planning methods (R3.2, R3.3, R3.4) that are integrated with HIV prevention and treatment, and maternal care (R3.5, R3.6).

The National Adolescent SRH Policy (2015) requires enhancing the provision of high-quality post-abortion services to adolescents, which includes contraceptives (R3.7). No legal documents in Kenya address the elimination of financial barriers for adolescents (R3.2), mobile outreach services (R3.8), nor third-party / parental authorisation (R3.9, R3.10). 


\section{Acceptability}

Acceptability refers to gender-sensitive counselling and educational interventions (R4.1) and follow-up services for the management of contraceptive side-effects (R4.2).

These recommendations were not addressed in Uganda's policies currently in force. Kenya's Adolescent SRH Policy (2015) takes a gender-sensitive approach to interventions (R4.1) by promoting male involvement in the prevention of early and unintended pregnancy. Neither Ugandan nor Kenyan policies include R4.2 in relation to adolescents.

\section{Quality}

Quality refers to quality assurance processes for standards of care and client feedback (R5.1), services for the provision and follow-up of LARC methods (R5.2), and competency-based training and supervision of healthcare personnel (R5.3).

Current policies in Uganda and Kenya do not refer to recommendations 5.1-5.2 for adolescent contraception. Kenya's Family Planning Cost Implementation Plan (2017-2020) refers to competency-based training and supervision of healthcare personnel (R5.3) for the practical application of family planning skills, adolescentfriendly service approaches, and internships for graduates to enhance their family planning service provision.

\section{Informed decision-making}

Informed decision-making requires evidence-based, comprehensive information, education and counselling (R6.1) and the assurance that every individual has the opportunity to make an informed choice about their use of modern contraceptives (R6.2).

Uganda's Family Planning Cost Implementation Plan 2015-2020 references provisions for empowering adolescents (age 10-24 years) to use family planning services and AYF information channels with the objective of empowering youth to avoid teenage pregnancy. However, evidence-based information about a range of methods for comprehensive, informed choices is not addressed in relation to adolescent contraception (R6.1), nor is the use of modern contraception without discrimination (R6.2).

Kenya's Family Planning Cost Implementation Plan 2017-2020 promotes behavioural change to address myths and misconceptions to improve acceptance and continued use of family planning with a special focus on age-appropriate information, access, and the use of family planning among adolescents (ages 10-24). This policy alludes to the importance of contraceptive information, counselling, and education to ensure informed choice
(R6.1) about own use of modern contraception without discrimination (R6.2) in relation to adolescents. Kenya's National Guidelines for Provision of AYF Services (2016) requires that contraception counselling and the full range of contraceptive methods are in essential packages of AYF services (R6.2).

\section{Privacy and confidentiality}

Privacy and confidentiality refer to the respect of an individual's privacy through the provision of contraception and confidentiality of medical and personal information (R7.1). Uganda's 2012 Adolescent Health Policy Guidelines \& Service Standards emphasise the offer of confidential counselling and information and provision of family planning to adolescents. Kenya's National Adolescent SRH Policy 2015 requires that all adolescent SRH services in this policy (including contraception) should be offered in a non-judgmental and confidential way.

\section{Participation}

Participation encompasses the involvement of people directly affected by policies to have the opportunity to be meaningfully engaged in all aspects of programme and policy design (R8.1).

Uganda's Family Planning Cost Implementation Plan (2015-2020) specifically seeks to align with other national policies and strategies and strengthen family planning policy environment including through the participation of women, adolescents, and marginalised and excluded groups.

Kenya's National Adolescent SRH Policy 2015 seeks to strengthen 'community involvement' to prevent early and unintended pregnancies. This policy seeks to involve adolescents in the planning, implementation, monitoring and evaluation of adolescent SRH programmes.

\section{Accountability}

Accountability requires that effective and accessible mechanisms exist for the delivery of contraceptive information and services to adolescents (R9.1) as well as programme evaluation and monitoring to ensure the highest quality services and respect of human rights (R9.2). Neither Uganda's nor Kenya's documents address these recommendations towards adolescents.

\section{Discussion}

These results illustrate that the current Ugandan and Kenyan policy landscapes for adolescent contraception include important references to human rights and evidence-based practice (in WHO's recommendations); 
however, there is still room for improvement. Ugandan policies include infrequent (one-off) recommendations for $6 / 9$ WHO recommendations, commonly in relation to contraception accessibility for adolescents. However, Ugandan policies miss entirely WHO's recommendations for adolescent contraception availability, quality, and accountability. On the other hand, most Kenyan policies consistently address multiple WHO recommendations, most frequently for contraception availability and accessibility for adolescents. Kenyan policies cover $8 / 9 \mathrm{WHO}$ recommendations except for accountability. In light of the key policy gaps identified in this study, we provide specific recommendations based on WHO's guidance and the inter-country comparison for both Uganda and Kenya (see Table 3).

Inconsistencies in the content of different adolescent SRH-related laws and policies are a recognised challenge to sound policy implementation in the SubSaharan African region [25, 26]. One example from our study illustrates this challenge: The Ugandan National HIV/AIDS Strategic Plan (2015-2020) seeks to scaleup comprehensive SRH/HIV programs targeting adolescents (both in and out of school) by providing AYF services including condom use and family planning information and commodities [27]. In 2016, the Ugandan government introduced a parliamentary ban on 'comprehensive' sexuality education (beyond abstinence only) [28]. This ban was repealed in 2018 with the launch of the National Sexuality Education Framework for adolescents, which does not include condom or contraceptive use [12, 29]. As a result, Uganda has two incoherent policy frameworks in force with regards to the provision of information about contraception to adolescents. Notably, these policies were adopted by different government bodies (Ugandan HIV/AIDS Commission vs. Ministry of Education and Schools), which could further explain the incoherent content. In our study, recommendations for adolescent contraception were predominantly located in policies adopted by the ministries of health or medical services; no such recommendations were identified in policies adopted by the ministries of education (Table 1 ). There is need therefore to harmonise national laws and policies across sectors for clarity and coherence, which is essential to sound implementation. In addition, a comparison of policy provisions at the national and sub-national levels would be an added value to understand how national framework legislation and policies are formulated, interpreted and applied. Kenya and Uganda are optimal sites for such future research given the decentralisation of health services in 47 counties and 134 districts, respectively. For example, the Makueni County adopted its Maternal and Newborn Child Health Act of
2017, which forbids the sale of condoms to adolescents and children but allows for the sale of any other form of contraception to adolescents who have a high chance of sexual exposure [30]. While our study did not systematically investigate the scope and frequency of policy inconsistencies, they are a major challenge for effective policy implementation and should be further investigated in subsequent research.

This study identified 67 national laws and policies with the potential to address nine domains of adolescent contraception. Of these, only 26 policies had any detailed recommendations for adolescent contraception. This could be the result of public or political opposition to adolescent contraception and a preference for 'watereddown' policy statements that do not capture AYF services and information related to contraception. For example, Kenya's older policies do not include contraception for this reason [31].

This study also illustrates some strengths of Ugandan and Kenyan policy with respect to adolescent contraception (described in the Results). Although a robust policy can create a supportive environment for adolescent contraception, its greatest impact can only be achieved when it is coupled with sound policy implementation. Contraceptive and SRH policy implementation relies on the six building blocks of health systems (including governance, political will, and leadership, adequate financial resources, a skilled and motivated health workforce, reliable and quality service delivery, health information systems, and access to contraceptive commodities), which are persistent challenges in Kenya, Uganda, and other neighbouring countries [25, 31, 32]. However, to the authors' knowledge, no literature explores how effectively or efficiently the policies in this study were implemented in practice. Yet the consistently low rates of modern contraceptive use among adolescent girls (described below) in Uganda and Kenya suggest that even strong policies are lacking consistent implementation. Drawing on recommendations for policy implementation in other SubSahara African countries, several focal points could also enhance the implementation of Kenyan and Ugandan policies. First, further research on policy implementation that includes 'robust, pragmatically designed' evaluation is needed [25]. Monitoring and evaluating the implementation of existing policy frameworks is the first step to addressing barriers to adolescent contraception. Second, implementers are advised to anticipate possible tensions in the policy roll-out (ex. between some health providers' beliefs or religious communities and policy goals) and proactively develop mitigation strategies [25]. Third, greater cohesion between policy actors, such as donors, governmental ministries or agencies (addressed above), should be sought [25]. 
Table 3 Key areas of improvement for Ugandan and Kenyan policy frameworks, based on WHO's recommendations

\section{WHO 9 main recommendations Priority improvements to current policies in Uganda and Kenya (Recommendations are for both countries unless otherwise indicated)}

1. Non-discrimination

2. Availability

3. Accessibility

4. Acceptability

5. Quality

6. Informed decision-making

7. Privacy and confidentiality

8. Participation

9. Accountability
No specific recommendations

For Uganda only, policy documents should consistently:

2.1: Prioritise the continuous supply of contraceptive commodities and supplies available through AYF service delivery points

2.1: Ensure the full financing of family planning commodities in the public and private sectors to prevent stock-outs that affect adolescents

3.2: Eliminate financial barriers to contraceptive use by marginalized populations including adolescents and the poor, and make contraceptives affordable to all

3.8: Ensure mobile access services are used to improve access to contraceptive information and services for adolescents who face geographical barriers to access

For Uganda only: 3.8: Establish different service delivery models to reach adolescents through community based initiatives in non-medical settings (i.e. youth groups, churches, support groups, etc.), clinical settings, school settings, and virtually including through digital platforms

3.9-3.10: Eliminate third-party authorisation requirements, including spousal and parental authorisation for adolescents accessing contraceptive information and services

For Uganda only: 4.1: Ensure gender-sensitive counselling and educational interventions on family planning and contraceptives for adolescents

For Uganda only: 4.1: Prioritise programmes for male involvement in the prevention of early and unintended pregnancy among adolescents

For Uganda only: 4.1: Establish community-based service delivery points and distribution of contraception to reach first time parents or young mothers whose mobility is limited, as well as to engage with adolescent couples and fathers in their new parenting roles

4.2: Provide adolescents with follow-up services for management of contraceptive side-effects as an essential component of all contraceptive service delivery

4.2: Provide adolescents with referrals for methods not available on site be offered and available

5.1: Ensure quality assurance processes, including medical standards of care and client feedback, be incorporated routinely into contraceptive programmes for adolescents

5.2: Provide long-acting reversible contraception (LARC) methods to adolescents, including insertion and removal services, and counselling on side-effects, in the same locality

For Uganda only: 5.3: Ensure ongoing competency-based training and supervision of health-care personnel on the delivery of contraceptive education, information and services to adolescents

For Uganda only: 5.3: Strengthen human resources and skills, build capacity on all FP methods, strengthening preservice training for practice, AYF service approaches, and create internship training for new graduates

6.1-6.2: Provide evidence-based information about a range of methods for comprehensive, informed choices, and the use of modern contraception without discrimination to adolescents

7.1: Respect the privacy of adolescents at any service delivery point (AYF or otherwise), particularly regarding contraceptive information and services

8.1: Ensure that communities, particularly adolescents directly affected, have the opportunity to be meaningfully engaged in all aspects of contraceptive programme and policy design, implementation and monitoring for adolescents

9.1: Establish effective accountability mechanisms that are accessible for adolescents in the delivery of contraceptive information and services, including monitoring and evaluation, and remedies and redress, at the individual and systems levels

9.1: Ensure that adolescents have easy access to a complaints mechanism or ombudsperson who can help assess and remedy barriers to accessing contraception in a timely way for the individual in question and on a systems level 9.2: Evaluate and monitor all programmes to guarantee the highest quality of services and respect for human rights particularly for adolescents

9.2: Include indicators specific to adolescents, including the teenage pregnancy rate and inclusion of women who are unmarried in the calculation of unmet need for contraceptive services

9.2: In settings where performance-based financing (PBF) occurs, provide a system of checks and balances for adolescents, including assurance of non-coercion and protection of human rights. If PBF occurs, evaluate its effectiveness and its impact on adolescents in terms of increasing availability 
Population health indicators illustrate the historical evolution in SRH outcomes in Uganda and Kenya, although no causal relationship between policy changes and outcomes can be determined. The maternal mortality ratio (MMR) has decreased from 468 (2011) to 336 (2016) per 100,000 live births in Uganda and from 520 (2008) to 362 (2014) per 100,000 live births in Kenya. This is partly due to the increased percentage of women using modern methods of family planning from 8 (1995) to $35 \%$ (2016) in Uganda and from 39 (2008) to 53\% (2014) in Kenya. However, the current use of modern contraceptives among adolescent girls aged 15-19 (who are sexually active and do not want a child in the coming two years) is still low in both countries at 39\% in Uganda and 46\% in Kenya $[33,34]$. Despite the improvements, neither country met the MDG targets on maternal mortality and neither are likely to meet the SDG target 3.1 of reducing MMR to $70 / 100,000$ live births unless adolescent contraception is improved $[7,8]$. To make progress towards the SGD targets, policy makers should utilise WHO's comprehensive list of recommendations to promote adolescent SHR and human rights and ensure their implementation.

The social, political, economic, and public health determinants influencing Uganda and Kenya's respective policy choices for adolescent contraception have been identified but a political solution has not been reached to address the challenges [29, 31, 35-37]. For example, in both countries, adolescents aged below 18 years are considered children which brings moral questions for age of consent to contraceptive services and therefore the policies remain silent over the issue [12, 15]. Structural barriers in the health system impair service provision such as inadequate physical space in clinics for adolescent contraception 'corners', insufficient human resources to staff those corners, and lack of availability of contraceptives affect access to contraceptives for adolescents [29, 31, 35-37]. Future research should investigate the factors that determine the political priority accorded to SRH, and specifically adolescent contraception as a national policy issue. For example, the new Reproductive Healthcare Bill proposed in 2019 in Kenya is a unique opportunity to study political priority for adolescent reproductive health in real-time because it obliges the State to formulate and implement a national strategy and plan of action to realise the right to reproductive health including a specific part on the provision of AYF reproductive health care services [38].

This study's strengths are its use of primary sources (legal documents in their original language), its consideration of any legal instrument related to adolescent contraception (although not necessarily published by the Ministries of Health), and its use of the WHO recommendations as a standard measure of comparison.
WHO's guidelines were a useful analytical framework for inter-country comparison, including with previous results from South Africa, the Philippines, and Paraguay [16-18]. However, WHO's guidelines only allow researchers to indicate whether a policy is aligned (or not) with WHO's best practice, but not whether national policy is regressive. For example, WHO's recommendations assess whether information on contraceptives is given during or after abortion services, but do not evaluate if legal or accessible safe abortion is a policy priority. The risk of interpretation error was minimised by relying on the definitions of terms and concepts in the policies themselves or, if not provided in the policies, as provided by the $\mathrm{MoH}$. This paper examines national laws and policies adopted between 2010 and 2018, which extends before the 2014 WHO guidelines on ensuring human rights in the provision of contraception were published. On one hand, we can expect that the early laws and policies may not embody WHO's guidance. On the other hand, WHO guidelines are often based on new initiatives (be it in law or policy) and/or the best practices of several countries. The study does not examine the implementation of policies and their intermediate (such as budget allocation) nor final outcomes (such as better access for adolescents to contraceptives). No traditional stakeholder validation meeting could be held in Kenya due to the travel restrictions and social distancing measures adopted in response to the Coronavirus pandemic.

\section{Conclusion}

Policies in Uganda and Kenya address human rights aspects in the provision of contraceptive information and services to adolescents. However, Kenya's policies address more of WHO's recommendations for adolescent contraception than Uganda's policies. This study highlights strengths, gaps, and areas of incoherence in policies on adolescent contraception in Uganda and Kenya, which are areas of action in future policy frameworks, such as Uganda's future (national) Adolescent Health Policy and the Reproductive Healthcare Bills that are adopted at the level of Kenyan counties. Aligning national laws and policies with WHO's recommendations on contraceptive information and services for adolescents may support interventions to improve health outcomes, provided these legal frameworks are effectively implemented.

\section{Abbreviations}

ART: Antiretroviral therapy; AYF: Adolescent- and youth-friendly; EAC: East African Community; HIV: Human immunodeficiency virus; LARC: Long acting reversible contraceptive; MDG: Millennium development goals; MMR: Maternal mortality rate; $\mathrm{MoH}$ : Ministry of Health; PBF: Performance-based financing; SDGs: Sustainable development goals; $\mathrm{SRH}$ : Sexual and reproductive health; WHO: World Health Organization. 


\section{Supplementary Information}

The online version contains supplementary material available at https://doi. org/10.1186/s12978-021-01303-8.

Additional file 1. List of documents screened for inclusion in the article 'A comparative human rights analysis of laws and policies for adolescent contraception in Uganda and Kenya'.

\section{Acknowledgements}

The authors acknowledge Ms. Caoimhe Cotter, Ms. Tabitha Saoyo Griffiths (TSG), and Mr. David Kabanda (DKA) for their research assistance, and the attendees of the 2019 ANSER week conference (Ghent, Belgium) and the Utrecht University/WHO Collaborating Centre 2020 Winter Pharmaceutical Policy Meeting (Utrecht, the Netherlands) for their helpful feedback.

\section{Authors' contributions}

KP and DK conceptualised the paper and collected the data. EW and CP analysed the data and together with KP, DK, JO, HvdH, AM-T, and KM interpreted the data. KP and DK drafted the manuscript, and EW, CP, JO, HvdH, AM-T, and $K M$ revised the article for important intellectual content. All authors read and approved the final manuscript.

\section{Funding}

This work was supported by VLIR-UOS and the Belgian Department of Development Cooperation's Global Minds programme, Brussels, Belgium. KP also received funding as a Post Doctoral Research Fellow at the Dalla Lana School of Public Health, University of Toronto, to complete this research. The funders had no role in the study design; the collection, analysis, and interpretation of data; the writing of the report; nor the decision to submit the manuscript for publication.

\section{Availability of data and materials}

All data analysed during this study were collected from publicly available documents listed in Table 1 and Additional file 1.

\section{Declarations}

\section{Ethics approval and consent to participate}

Not applicable.

\section{Consent for publication}

Not applicable.

\section{Competing interests}

The authors declare that they have no competing interests.

\begin{abstract}
Author details
'International Centre for Reproductive Health, Department of Public Health and Primary Care, Ghent University, C. Heymanslaan 10, 9000 Gent, Belgium. ${ }^{2}$ Amsterdam Law School, University of Amsterdam, Amsterdam, The Netherlands. ${ }^{3}$ Academic Network on Sexual and Reproductive Health and Rights Policy (ANSER), Ghent University, C. Heymanslaan 10, 9000 Gent, Belgium. ${ }^{4}$ Coalition for Health Promotion and Social Development (HEPS-Uganda), Plot 351A, Balintuma Road, Namirembe Hill, Kampala, Uganda. ${ }^{5}$ Department of Journalism and Media Studies, Faculty of Social Sciences and Technology, Technical University of Kenya, P.O. Box 52428, Nairobi, Kenya. ${ }^{6}$ Division of Pharmacoepidemiology and Clinical Pharmacology, Utrecht Institute for Pharmaceutical Sciences (UIPS), Utrecht University, Universiteitsweg 99, 3584 CG Utrecht, The Netherlands.
\end{abstract}

Received: 27 October 2020 Accepted: 4 December 2021

Published online: 07 February 2022

\section{References}

1. Langer A, Meleis A, Knaul FM, Atun R, Aran M, Arreola-Ornelas H, et al. Women and Health: the key for sustainable growth. Lancet. 2015;386(9999):1165-210
2. Patton GC, Coffey C, Sawyer SM, Viner RM, Haller DM, Bose K, et al. Global patterns of mortality in young people: a systematic analysis of population health data. Lancet. 2009;374(9693):881-92.

3. Denno DM, Hoopes AJ, Chandra-Mouli V. Effective strategies to provide adolescent sexual and reproductive health services and to increase demand and community support. J Adolesc Health. 2015;56(1 Suppl):S22-41.

4. Svanemyr J, Amin A, Robles OJ, Greene ME. Creating an enabling environment for adolescent sexual and reproductive health: a framework and promising approaches. J Adolesc Health. 2015;56(1 suppl(s7)):7-14.

5. Pugh S. Politics, power, and sexual and reproductive health and rights: impacts and opportunities. Sex Reprod Health Matters. 2019;27(2):1-5.

6. Chandra-Mouli V, McCarraher DR, Phillips SJ, Williamson NE, Hainsworth G. Contraception for adolescents in low and middle income countries: needs, barriers, and access. Reprod Health. 2014;1 1(1):1.

7. Kenya National Bureau of Statistics, Ministry of Health/Kenya, National AIDS Control Council/Kenya, Kenya Medical Research Institute, National Council for Population and Development/Kenya. Kenya Demographic and Health Survey 2014. Rockville, Maryland USA: 2015

8. Uganda Bureau of Statistics and ICF. Uganda Demographic and Health Survey 2016: Key Indicators Report, Kampala, Uganda, Rockville, Maryland, USA: 2017.

9. Ministry of Health Kenya. National Adolescent Sexual and Reproductive Health Policy. . Nairobi, Kenya: Ministry of Health Kenya, 2015.

10. Watson C, Muhanguzi FK, Bantebya GK. From national laws and policies to local programmes: obstacles and opportunities in communications for adolescent girls' empowerment in Uganda. In empowering adolescent girls in developing countries. 20182018 Feb. Report No.

11. Larsson S, Eliasson M, Allvin MK, Faxelid E, Atuyambe L, Fritzell S. The discourses on induced abortion in Ugandan daily newspapers: a discourse analysis. Reprod Health. 2015;12(1):58.

12. Ministry of Education and Sports Uganda. National Framework on Sexuality Education. Kampala, Uganda: Ministry of Education and Sports, 2018

13. De Haas B, Hutter I. Teachers' conflicting cultural schemas of teaching comprehensive school-based sexuality education in Kampala, Uganda. Cult Health Sex. 2019;21(2):233-47.

14. East African Community Legislative Assembly (EALA). HIV and AIDS Prevention and Management Act of 2012. Arusha, Tanzania: East African Community Legislative Assembly:; 2012.

15. World Health Organisation. Ensuring human rights in the provision of contraceptive information and services. Geneva: Switzerland; 2014.

16. Hoopes AJ, Chandra-Mouli V, Steyn P, Shilubane T, Pleaner M. An analysis of adolescent content in South Africa's contraception policy using a human rights framework. J Adolesc Health. 2015;57(6):617-23.

17. Cordova-Pozo K, Borg S, Hoopes AJ, Camacho-Hubner AV, Corrales-Ríos F, Salinas-Bomfim A, et al. How do national contraception laws and policies address the contraceptive needs of adolescents in Paraguay? Reprod Health. 2017. https://doi.org/10.1186/s12978-017-0344-z.

18. Melgar JLD, Melgar AR, Festin MPR, Hoopes AJ, Chandra-Mouli V. Assessment of country policies affecting reproductive health for adolescents in the Philippines. Reprod Health. 2018;15(1):205.

19. Cordova-Pozo KL, Cordova-Pozo G, Monza A, Píriz G, Moreno-Lopez D, Cardenas I. Sexual and reproductive rights for contraception in Bolivia, Colombia and Uruguay in the framework of human rights. Rev Panam Salud Pública. 2017. https://doi.org/10.26633/RPSP.2017.140.

20. United Nations Population Fund (UNFPA) and WHO. Ensuring human rights within contraceptive service delivery: implementation guide, 2015 Geneva: 2015.

21. Mandira $P$, Näsström SB, Klingberg-Allvin M, Kiggundu C, Larsson EC. Healthcare providers balancing norms and practice: challenges and opportunities in providing contraceptive counselling to young people in Uganda_-a qualitative study. Glob Health Act. 2016;9(10):30283.

22. Lobo J, Bhatia R, Naqvi S. A policy description language. NJ: Bells Lab; 1999.

23. Every Woman Every Child and Partnership for MNCH. Progress in partnership: progress report on the every woman every child global strategy for women's. Geneva: Children's and Adolescents' Health; 2017.

24. United Nations. Global Strategy for Women's and Children's and Adolescents Health (2016-2030) Italy: 2015

25. Davids EL, Kredo T, Gerritsen AAM, Mathews C, Slingers N, Nyirenda M, et al. Adolescent girls and young women: policy-to-implementation gaps 
for addressing sexual and reproductive health needs in South Africa. S Afr Med J. 2020;110(9):855-7.

26. Dube K, Van der Putten M, Vajanapoom N. Adolescent health, global guidelines versus local realities: the Sub-Saharan Africa experience. J Public Health Africa. 2013;4(2): e12.

27. Uganda AIDS Commission. National HIV/AIDS Strategic Plan 2015/20162019/2020. Kampala, Uganda: Uganda AIDS Commission, 2015

28. Boozalis JA, Nakibuule MH, Realini JP, Rosenfeld J. A new hope: introducing comprehensive sex education to a Christian secondary school in Uganda after repeal of parliamentary ban. J Glob Health Rep. 2020;28(4): e2020024.

29. Onono MA. Generating political priority for adolescent sexual and reproductive health in Kenya: problem definition, priority setting processes, and contraception (Doctoral dissertation, UCSF). University of Carlifornia San Franscisco; 2019.

30. Makueni County Maternal, Newborn, and Child Health Bill of 2017 (2017).

31. Akwara E, Idele P. The moral and social narratives of sexual and reproductive health in Kenya: a case of adolescents and young people pre- and within the MDG era. Reprod Health. 2020;17(75):1-12.

32. Rutaremwa G. Factors associated with adolescent pregnancy and fertility in Uganda: analysis of the 2011 demographic and health survey data. Am J Sociol Res. 2013;2(1):7-13.

33. Guttmacher Institute. Adding it up: Investing in contraception and maternal and newborth health for adolescents in Uganda (Factsheet) New York: Guttmacher Institute; 2018 [updated December 20 201823rd February 2021]; https://www.guttmacher.org/fact-sheet/adding-it-upcontraception-mnh-adolescents-uganda.

34. Guttmacher Institute. Adding it up: investing in contraception and maternal and newborth health for adolescents in Kenya, 2018. [Factsheet] New York2019 [updated February 2019 23rd February 2021]; https:// www.guttmacher.org/fact-sheet/adding-it-up-contraception-mnh-adole scents-kenya.

35. Crichton J. Changing fortunes: analysis of fluctuating policy space for family planning in Kenya. Health Policy Plan. 2008;23(5):339-50.

36. Bijlmakers $L$, de Haas $B$, Peters A. The political dimension of sexual rights. Reprod Health. 2018. https://doi.org/10.1186/s12978-018-0458-y.

37. Ninsiima A, Coene G, Michielsen K, Najjuka S, Kemigisha E, Ruzaaza G, et al. Institutional and contextual obstacles to sexuality education policy implementation in Uganda. Sex Educ. 2019;20(53):1-16.

38. Republic of Kenya. Proposed reproductive healthcare bill of 2019. Supplement No 186. Nairobi: Kenya Gazette 2019.

\section{Publisher's Note}

Springer Nature remains neutral with regard to jurisdictional claims in published maps and institutional affiliations.

Ready to submit your research? Choose BMC and benefit from:

- fast, convenient online submission

- thorough peer review by experienced researchers in your field

- rapid publication on acceptance

- support for research data, including large and complex data types

- gold Open Access which fosters wider collaboration and increased citations

- maximum visibility for your research: over 100M website views per year

At BMC, research is always in progress.

Learn more biomedcentral.com/submissions 